\title{
PROPOSIÇÃO DE UM SISTEMA DE INVENTÁRIO FLORESTAL NACIONAL PARA O BRASIL
}

\section{NATIONAL FOREST INVENTORY SYSTEM PROPOSED TO BRAZIL}

\author{
Doádi Antônio Brena ${ }^{1}$
}

\begin{abstract}
RESUMO
O presente trabalho visa retomar a discussão do Inventário Florestal Nacional e propor as bases metodológicas e estruturais para sua implantação definitiva no Brasil. Propõe-se um sistema de inventário florestal nacional para o Brasil, com base na experiência internacional e na busca de soluções para os problemas detectados durante a realização do primeiro inventário florestal nacional. O sistema proposto analisa e sugere três estruturas principais: a institucional, a metodológica e a operacional. Do exposto no trabalho, conclui-se que o inventário florestal nacional é um instrumento auxiliar indispensável, para o planejamento e administração corretos dos recursos florestais, para responder às exigências de Certificação de Origem de produtos florestais, fornecer a base de informações necessária para a inserção do país no programa de qualidade total do meio ambiente a ser definido pela ISO 14.000, e para que os recursos florestais brasileiros possam oferecer uma contribuição sócio-econômica compatível com sua potencialidade.
\end{abstract}

Palavras-chave: Inventário florestal nacional (IFN), sistema.

\section{SUMMARY}

The purpose of this work is to bring back a discussion on the organization of the Brazilian National Forest Inventory and also propose the methodology and the necessary basic structure for its final establishment in the country. It proposes a national forest inventory system for Brazil, based on the evaluated international experience and on the detected problems occurred on the first conducted inventory. The proposed NFI system analyses and suggests three main structures: the institutional, methodological and operational ones. From what it is presented, it is possible to say that the national forest inventory is an important and required instrument for the planning and appropriate administration of the forest resources; to attend the required certification of the forest products; to assure the background and information for the participation of the country in the international environmental total quality program, that will be further defined by the ISO 14.000;

1. Engenheiro Florestal, Dr., Prof. Adjunto do Departamento de Ciências Florestais. UFSM. 97.119-900. Santa Maria. RS. 
and finally to bring into picture the participation of the Brazilian forest resources in the socioeconomical development of the country, compatible with their potentialities.

Key words: National Forest Inventory (NFI), system.

\section{INTRODUÇÃO}

A história demonstra, que a maioria dos países desenvolvidos utilizaram o capital oriundo dos recursos naturais, especialmente dos florestais, para alavancar seus processos de desenvolvimento. Hoje, esses países são detentores de coberturas florestais expressivas porque reconheceram, desde cedo, o valor e a importância dos recursos florestais, não só como fonte energética e de matéria-prima, mas principalmente para a conservação e estabilidade dos demais recursos naturais renováveis.

O Brasil também vem utilizando seus recursos florestais, desde seu descobrimento, como um dos fatores de promoção de seu desenvolvimento. Todavia, mesmo após 5 séculos, ainda não reconhece integralmente o valor e a importância dos mesmos. Apesar de contar com uma legislação florestal e ambiental satisfatória, continua usando seus recursos florestais sem critérios técnicos apropriados e uma base sólida de informações, que permita definir onde, quando, como e em que quantidade estes recursos podem ser utilizados.

Um sistema de Inventário Florestal Nacional (IFN) poderá suprir estas deficiências e alterar a administração atual dos recursos, centrada em ações de fiscalização e poucas ou nenhuma ação de desenvolvimento.

A Certificação de Origem dos Produtos Florestais, exigida pelo mercado internacional, representa o primeiro passo no sentido de inserir os países produtores no programa de qualidade total do meio ambiente. E, neste aspecto, o IFN assume sua maior importância, uma vez que não se pode implantar um programa de qualidade para algo que não se conhece.

As informações periódicas do IFN forneceriam as bases decisórias para a definição e implementação de políticas florestais, para o aprimoramento da legislação florestal e ambiental, para a implementação do programa de qualidade ambiental, e elaboração de planos de curto, médio e longo prazos, para o desenvolvimento, conservação e uso sustentado dos recursos florestais.

\section{BASES PARA A ESTRUTURAÇÃO DO SISTEMA}

O sistema de IFN considera alguns aspectos básicos, que são indispensáveis ou que podem auxiliar sua implementação:

a) O grande número de inventários florestais realizados no país, por vezes superpostos, poderiam ser evitados ou integrados ao sistema;

b) O Programa de Monitoramento da Cobertura Florestal da Amazônia constitui o único levantamento sistematizado de florestas realizado no país;

c) O Brasil não dispõe de fotografias aéreas atualizadas e em escala adequada;

d) As cartas geográficas do Exército necessitam atualização;

e) O Brasil possui um mapa padronizado dos recursos florestais, elaborado pelo Projeto 
RADAMBRASIL, que cobre todo o país;

f) O Estado de São Paulo possui base cartográfica digitalizada, com mapa atualizado da cobertura florestal na escala 1:50.000;

g) O uso exclusivo de imagens de satélite no sistema apresenta limitações, mas poderiam ser usadas para atualizar os mapas do Projeto RADAMBRASIL;

h) O sistema deverá envolver técnicas modernas de processamento de dados, tratamento de imagens, transmissão remota de informações e o emprego de um sistema de informações geográficas;

i) O sistema deverá contar com o apoio e suporte científico das Universidades que possuem Cursos de Engenharia Florestal, da EMBRAPA, INPE, INPA e outras instituições de pesquisa.

\section{OBJETIVOS DO SISTEMA}

O objetivo principal do sistema é fornecer informações contínuas, atualizadas, suficientes e confiáveis sobre o estado dos recursos florestais e suas mudanças com o tempo, para embasar planos estratégicos de desenvolvimento e uso das florestas.

Os objetivos específicos do sistema são apresentados em linhas gerais, enfocando a área coberta por florestas nativas e plantadas; composição florística e estrutura fitossociológica; quantificação do estoque de crescimento; regeneração natural; ingresso ou recrutamento, crescimento e mortalidade; cortes periódicos; danos florestais; desmatamento; uso múltiplo; condição silvicultural das florestas e práticas necessárias; fauna silvestre; uso atual da terra; parâmetros recreacionais e eco-turísticos.

\section{CARACTERÍSTICAS GERAIS DO SISTEMA}

Analisando-se a experiência internacional e reportando-se à realidade florestal brasileira, propõe-se um sistema de IFN para o Brasil, com as seguintes características gerais, em conformidade com CUNIA (1985 p.6-17):

a) Sistema independente, para garantir uniformidade de definições, critérios, procedimentos de levantamento, e referência temporal das informações;

b) Sistema com estrutura de amostragem estatisticamente apropriada, eficiente e sem tendências, para fornecer estimativas válidas dos parâmetros de interesse, com os respectivos erros;

c) Sistema amplo, integrado e de múltiplos recursos da floresta, que envolva todos os seus recursos, incluindo biomassa total, frutos, casca, sementes, látex e resinas, etc., bem como a vegetação, solo, água, animais silvestres e seus habitats, insetos, potencial de uso múltiplo, recreação, turismo, entre outros;

d) Sistema flexível e dinâmico, que permita fácil adaptação a inovações tecnológicas, novas necessidades de informações e de precisão.

A proposição do sistema de IFN para o Brasil foi elaborada, a partir da análise e definição de três estruturas principais: a institucional, a metodológica e a operacional (BRENA, 1995). 


\section{ESTRUTURA INSTITUCIONAL DO SISTEMA}

A análise da experiência internacional evidenciou diferentes organizações institucionais usadas para a realização de IFN, como seguem:

- Na Europa, a Suécia realiza seu IFN através do Departamento de Levantamentos Florestais, criado com esta finalidade na Escola de Florestas da Universidade de Ciências Agrícolas da Suécia (ERIKSSON, 1985); o da Finlândia é conduzido pelo Instituto Finlandês de Pesquisa Florestal, ligado ao Ministério da Agricultura e Florestas (KUUSELA, 1985); o da Suíça é coordenado pela Agência Federal de Florestas e executado pelo Departamento de Inventário Florestal Nacional do Instituto Federal de Pesquisas Florestais (MAHRER, 1985); o da Holanda é um projeto cooperativo entre o Serviço Florestal, do Ministério da Agricultura e a Agência Central de Estatísticas do Ministério da Economia (JANSEN et alli, 1985); e o da Espanha é realizado pela Seção de Inventários e Mapas do Instituto para a Conservação da Natureza (MARTÍNEZ MILAN, 1985).

- Na América do Norte, o IFN dos Estados Unidos é realizado pelas unidades de Inventário Florestal e Análises (FIA), situadas nas Estações Experimentais Florestais, do Serviço Florestal do Departamento de Agricultura (USDA Forest Service), através de projetos regionais independentes (SCHREUDER \& BONNOR, 1987); o IFN do Canadá resulta dos inventários das Províncias, realizados pelos Órgãos Florestais Provinciais, de modo autônomo e independente (BONNOR, 1982).

- Na América Latina, o México realiza seu IFN através do Instituto de Investigações Florestais, da Subsecretaria Florestal e da Fauna (BERMUDEZ, 1982).

- No Brasil, o IFN é uma atribuição do Ministério do Meio Ambiente, o qual deve ser realizado pelo Instituto Brasileiro do Meio Ambiente e Recursos Naturais Renováveis. Como a Constituição Federal estabelece a execução concorrente da política florestal e ambiental nos Estados pelos governos estaduais, a estrutura institucional deve integrar e articular as esferas federal e estadual de competências e decisões.

A estrutura institucional do IFN poderia seguir a sugestão apresentada por PÉLLICO NETTO (1981), com as adequações necessárias, organizada em três níveis operativos, caracterizando uma concepção integrativa de opiniões e uma estrutura descentralizada de execução. Os três níveis operativos seriam: uma coordenação política nacional, uma coordenação técnica nacional e coordenações técnicas regionais.

\section{Coordenação política nacional}

A coordenação política nacional, integrada pelos governos federal e estaduais, teria a função de formular os objetivos gerais a serem alcançados pelo IFN. Esta coordenação, liderada pelo Ministério do Meio Ambiente, deveria integrar os Ministérios que tenham interesse direto ou indireto nos resultados do inventário e as Secretarias Estaduais responsáveis pela execução da política florestal nos Estados. Os representantes destes órgãos constituiriam o Conselho Consultivo de Planejamento. 


\section{Coordenação técnica nacional}

A coordenação técnica nacional, com a participação de professores de Inventário Florestal das Escolas de Engenharia Florestal do país, teria a função de elaborar os planos técnicos e organizacionais necessários, para alcançar os objetivos gerais formulados pelo Conselho Consultivo de Planejamento, e coordenar todas as tarefas do inventário a nível nacional. Esta coordenação poderia ser realizada através de três alternativas de organização, visando racionalizar recursos financeiros, materiais e humanos:

a) A primeira, seria uma organização similar aquela utilizada para a realização do primeiro inventário nacional, onde o IBAMA coordenaria o levantamento a nível nacional e as Universidades executariam o trabalho em suas regiões de atuação.

b) A segunda alternativa, baseada no exemplo da Suécia, seria a reativação, pelo IBAMA, da Coordenação Técnica Nacional, composta por professores de Inventário Florestal das Escolas de Florestas, e sua instalação dentro de uma das Universidades, onde seria criada toda a infra-estrutura do levantamento.

c) A terceira alternativa, seria o IBAMA delegar a Coordenação Técnica Nacional do IFN para o Centro Nacional de Florestas da EMBRAPA, a exemplo da Suíça e México.

\section{Coordenações técnicas regionais}

As coordenações técnicas regionais seriam instaladas junto aos órgãos florestais dos Estados, ou das Universidades participantes do inventário, com a função de executar o levantamento nos Estados.

A estas coordenações caberia levantar as demandas de informações adicionais do inventário, junto aos setores público e privado, definir prioridades e analisar a possibilidade de inserí-las no levantamento, bem como processar os dados e elaborar os relatórios dos inventários dos Estados, manter cópias dos dados, mapas, fotografias aéreas, etc., e organizar bancos de dados e informações florestais.

\section{ESTRUTURA METODOLÓGICA DO SISTEMA}

\section{Periodicidade do IFN}

A experiência internacional mostra que a maioria dos países repete seus inventários nacionais a cada 10 anos, período que, no Brasil, seria adequada para as florestas nativas, mas não para as florestas plantadas de rápido crescimento.

Entretanto, a busca por informações sobre dinâmica e crescimento das florestas vem alterando a periodicidade dos inventários nacionais. A tendência, como já ocorre na Suécia e Finlândia, é repetir os inventários a cada 5 anos, mediante um processo anual contínuo em que $20 \%$ da estrutura total de amostragem é remedida a cada ano.

Diante disso, propõe-se que o IFN do Brasil seja implantado em 5 etapas, sendo uma região por etapa, em um período de 10 anos. E após a implantação, que o inventário seja repetido a cada 5 
anos.

\section{Organização administrativa do sistema}

Propõe-se que o IFN considere três níveis administrativos: as Regiões Geográficas, constituiriam regiões administrativas; as Unidades da Federação constituiriam unidades administrativas; e as Microrregiões Homogêneas do país constituiriam subunidades administrativas.

\section{Regiões administrativas} Tabela 1.

As cinco regiões administrativas do inventário, com sua área total, são apresentadas na

TABELA 1: Regiões administrativas, área total, ordem de implantação do inventário e tempo previsto para sua conclusão.

\begin{tabular}{|c|c|c|c|}
\hline REGIÃO ADM. & ÁREA TOTAL $\left(\mathrm{km}^{2}\right)$ & ORDEM & $\mathrm{ANO}$ \\
\hline Norte & 3.581 .180 & 1 & $1^{\circ}$ ao $4^{\circ}$ \\
\hline Centro-este & 1.879 .455 & 2 & $5^{\circ}$ e $6^{\circ}$ \\
\hline Nordeste & 1.548 .672 & 3 & $7^{\circ}$ e $8^{o}$ \\
\hline Sudeste & 924.935 & 4 & $9^{\circ}$ \\
\hline Sul & 577.723 & 5 & $10^{\circ}$ \\
\hline TOTAL & 8.511 .965 & & 10 \\
\hline
\end{tabular}

Dado a extensão territorial do país, a infra-estrutura, recursos humanos, materiais e financeiros necessários para a implantação total do inventário em curto espaço de tempo, propõe-se também nesta tabela a seqüência de execução do levantamento, partindo-se do Norte em direção ao Sul do país, e o tempo previsto para a conclusão de cada região administrativa.

\section{Unidades administrativas}

Os Estados, Território e Distrito Federal constituiriam 28 unidades administrativas do inventário, para as quais seriam apresentados resultados setorizados.

\section{Subunidades administrativas}

As subunidades administrativas seriam compostas pelas 360 Microrregiões Homogêneas do país. Dentro de cada unidade administrativa, as informações deveriam ser setorizadas por Microrregião Homogênea e, na medida do possível, por município.

\section{Mapeamento e classificação de áreas florestais}

O mapeamento da cobertura florestal dos Estados e do País seria realizado com base em 
fotografias aéreas ou imagens de satélite e radar. Em qualquer dos casos, visando manter uniformidade em nível nacional, deveria ser definido o mapa-base, sistema de classificação florestal, escalas e meios de atualização padronizados.

\section{Fotografias aéreas}

As fotografias aéreas disponíveis no país apresentam escalas e épocas de obtenção diferenciadas. Muitos Estados só dispõem de fotografias obtidas em 1975, na escala 1:100.000. Alguns poucos, possuem fotografias obtidas no início da década de 80, em escalas de 1:20.000 a 1:25.000. Estas fotografias poderiam servir de apoio aos trabalhos de campo, mas não para o mapeamento da cobertura florestal, devido a desatualização.

Analisando-se a experiência internacional em IFN constatou-se que a maioria dos países utilizam fotografias aéreas para o mapeamento de suas coberturas florestais.

Assim, no Brasil, o ideal seria a realização de um vôo em cada região. Estas fotografias aéreas poderiam ter escala entre 1:20.000 e 1:50.000, para atender, além do inventário, inúmeras utilizações em nível nacional, estadual e municipal.

A interpretação das fotografias seria transferida para uma base cartográfica e preparada para ser inserida em um sistema de informações geográficas, dotando o país de um instrumento moderno de planejamento, que facilitaria as atualizações futuras e o trânsito das informações entre as Instituições, através da informática.

\section{Imagens de satélite}

Além de fotografias aéreas, outra alternativa para o mapeamento da cobertura florestal seria o uso de imagens de satélite.

O uso único e exclusivo de imagens de satélite exige um intenso trabalho de campo para classificar diferentes tipos de vegetação, tipologias florestais ou espécies de florestas plantadas, o que na Região Amazônica, por exemplo, tornaria o inventário inexeqüível pelo seu custo final.

Entretanto, o problema poderia ser minorado com a associação de imagens de satélite e o mapa de vegetação produzido pelo Projeto RADAMBRASIL. Desse modo, o mapa base seria atualizado com a interpretação de imagens recentes, conservando-se a classificação da vegetação realizada pelo Projeto RADAMBRASIL.

Um aspecto importante a considerar é que parte da Região Amazônica foi mapeada pelo Programa de Monitoramento da Cobertura Florestal da Amazônia, com base em imagens de satélite. Assim, na Amazônia, o IFN poderia utilizar os mapas produzidos por esse Programa e solucionar o problema da classificação florestal, através da aplicação de um procedimento de amostragem em três estágios, onde o primeiro estágio seria a imagem de satélite; o segundo, as fotografias aéreas que cobrem a imagem e o terceiro estágio a unidade amostral de campo.

\section{Mapa base}

O mapa base mais apropriado para o IFN, quer usando fotografias aéreas atualizadas, quer 
usando imagens de satélite, é o do Projeto RADAMBRASIL, o qual apresenta duas características fundamentais, que são uniformidade e abrangência nacional. Além disso, uma pequena parte desse mapa foi preparada para ser inserida em um sistema de informações geográficas, o que facilita sua atualização.

\section{Escala dos mapas}

No mapeamento, é de fundamental importância a padronização das escalas de trabalho, as quais devem ser definidas a nível nacional, regional, estadual e municipal. Deve-se considerar também o precedente criado pelo Estado de São Paulo, que mapeou sua cobertura florestal na escala 1:50.000.

Diante disso, propõe-se as seguintes escalas para os diferentes níveis de informação $1: 1.000 .000 ; 1: 100.000 ; 1: 50.000$ e 1:25.000, para os níveis nacional, região administrativa, unidade administrativa e subunidade administrativa, respectivamente.

\section{Atualização dos mapas}

Os mapas obtidos durante a implantação do IFN seriam preparados para compor um sistema de informações geográficas. Assim, nas ocasiões sucessivas do inventário, esses mapas seriam atualizados através de novas fotografias aéreas ou imagens de satélite.

\section{Sistema de amostragem}

No planejamento do sistema de amostragem, para o IFN do Brasil, considerou-se os seguintes aspectos: o inventário seria do tipo contínuo, repetido a cada 5 anos; a experiência internacional mostrou que os sistemas de inventário mais eficientes usam estruturas amostrais temporárias e permanentes; as estruturas amostrais deveriam atender as particularidades das florestas nativas e plantadas e a Região Amazônica, devido a sua extensão e dificuldade de acesso, deveria receber uma estrutura de amostragem diferenciada, usando-se conglomerados distribuídos com uma maior distância entre eles.

\section{Processo de amostragem em múltiplas ocasiões}

O processo de amostragem em múltiplas ocasiões seria a amostragem com repetição parcial (ARP), com 50\% das unidades amostrais permanentes e 50\% temporárias, distribuídas sobre conglomerados permanentes e temporários, respectivamente. Os permanentes forneceriam informações de crescimento e dinâmica das florestas e os temporários, maior consistência sobre o estado das florestas em cada abordagem do inventário.

\section{Processo básico de amostragem}

Em conformidade com a experiência internacional, propõe-se a amostragem sistemática com pós-estratificação, como processo básico de amostragem para o IFN.

A amostragem sistemática seria organizada sobre redes de $10 \mathrm{~km} \times 10 \mathrm{~km}$ entre pontos, e 30 
km x 30 km na Região Norte. Nas interseções das linhas da rede, seria instalado um conglomerado temporário ou permanente, diferenciado de acordo com o tipo de floresta e, no caso de floresta nativa, das condições de acesso à área. A distribuição dos conglomerados, na rede sistemática, seria intercalada como mostra a Figura 1.

A partir da segunda abordagem, os conglomerados seriam instalados conforme propõe PÉLLICO NETTO (1981), através de um rodízio por quadrantes, dentro de sua área de influência, na seguinte seqüência: quadrantes noroeste (2), nordeste (3), sudeste (4) e sudoeste (5), para a segunda, terceira, quarta e quinta abordagens, respectivamente.

\section{Conglomerados}

Os conglomerados propostos, seriam de forma quadrada e de cruz, compostos por subunidades de área fixa, distribuídas a cada $100 \mathrm{~m}$ de distância nas florestas nativas e a cada $75 \mathrm{~m}$ nas florestas plantadas. Os conglomerados quadrados minimizam o deslocamento improdutivo no trabalho de campo; já os em forma de cruz facilitam sua instalação.

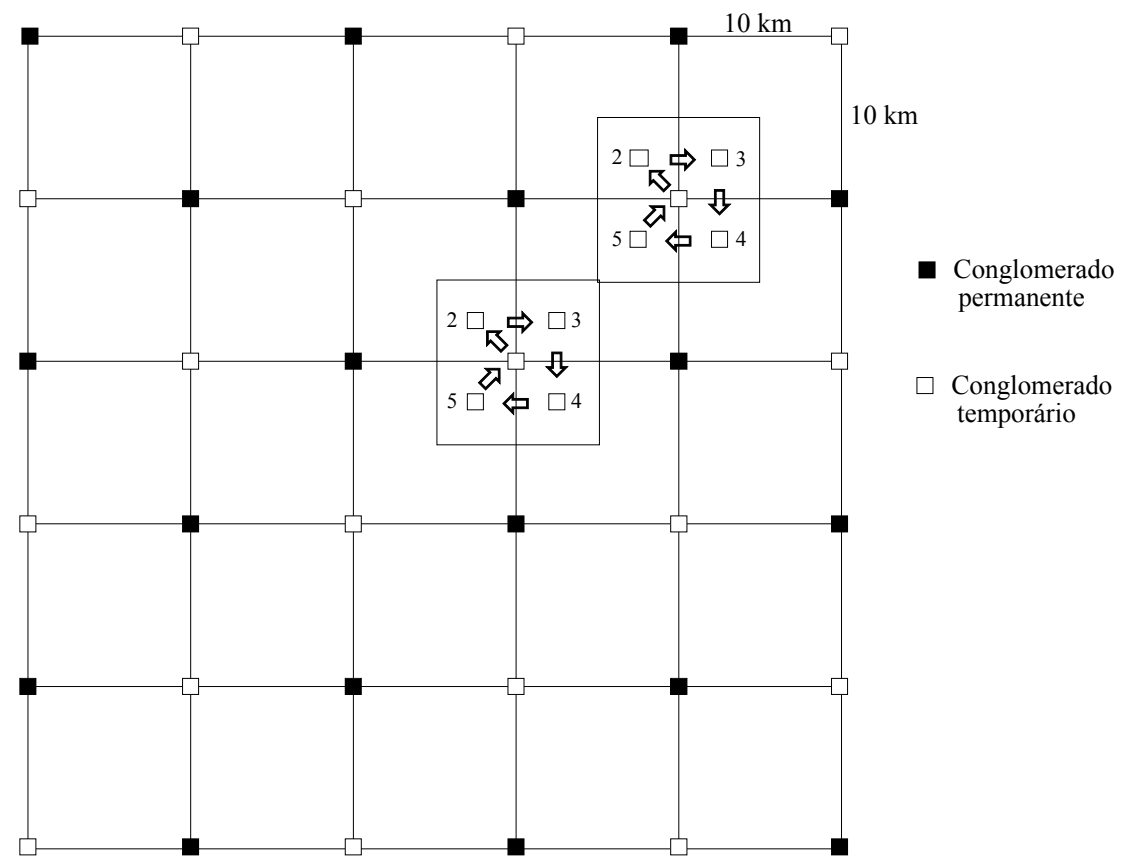

FIGURA 1: Distribuição dos conglomerados na rede sistemática e procedimento de rodízio propostos para o IFN do Brasil.

Uma pesquisa realizada na Finlândia, comparou conglomerados quadrados com conglomerados em forma de meio quadrado ("L"), de tal modo que o comprimento dos lados deste fosse igual ao perímetro do quadrado respectivo, e concluiu que a precisão do meio quadrado ("L") era maior do que a do quadrado. Isto leva a crer que um conglomerado em forma de cruz poderia obter resultados similares, em termos de precisão, e constituir uma alternativa a ser pesquisada e analisada. 
A distância de $100 \mathrm{~m}$ entre as subunidades do conglomerado é baseada nos trabalhos de PÉLLICO NETTO (1969) e QUEIROZ (1977), para a floresta tropical amazônica, os quais concluem que a distância ótima entre subunidades, na cruz de malta, é de 80 a $120 \mathrm{~m}$.

\section{Conglomerado para florestas nativas subtropicais}

Para as florestas nativas subtropicais, propõe-se um conglomerado quadrado composto por subunidades retangulares, com $20 \mathrm{~m}$ x $50 \mathrm{~m}\left(1.000 \mathrm{~m}^{2}\right)$, e diferenciado para três condições de acesso à área fácil, médio e difícil, como mostra a Figura 2.
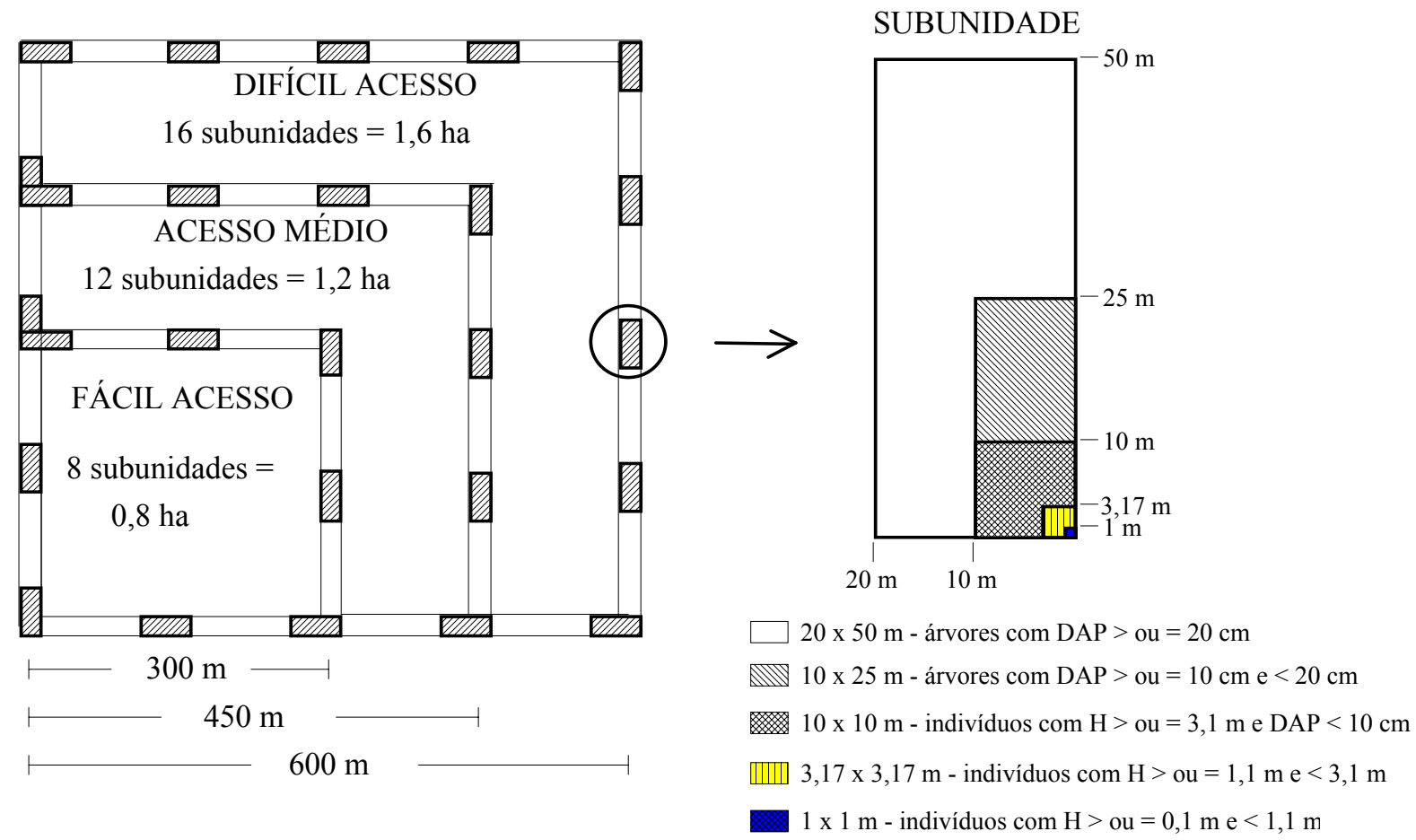

FIGURA 2: Conglomerado para florestas nativas subtropicais proposto ao IFN do Brasil.

Em condições de fácil acesso à área florestal, o conglomerado quadrado teria $300 \mathrm{~m}$ de lado e seria composto por 8 subunidades; em condições médias de acesso, $450 \mathrm{~m}$ de lado e 12 subunidades; e em condições de difícil acesso, $600 \mathrm{~m}$ de lado e 16 subunidades.

A subunidade seria padrão, para as florestas nativas subtropicais, constituída por um retângulo de $20 \mathrm{~m}$ x $50 \mathrm{~m}\left(1.000 \mathrm{~m}^{2}\right)$, na qual seriam levantadas as árvores com DAP $\geq 20 \mathrm{~cm}$. Esta subunidade seria dividida em 4 subamostras, um quadrado, com $1 \mathrm{~m}$ de lado $\left(1 \mathrm{~m}^{2}\right)$,

para o levantamento das ocorrências da regeneração com altura entre $\geq 0,1 \mathrm{~m} \mathrm{e}<1,1 \mathrm{~m}$; um quadrado, com $3,17 \mathrm{~m}$ de lado $\left(10 \mathrm{~m}^{2}\right)$, para o levantamento das ocorrências da regeneração com altura $\geq 1,1 \mathrm{~m} \mathrm{e}<3,1 \mathrm{~m}$; um quadrado, com $10 \mathrm{~m}$ de lado $\left(100 \mathrm{~m}^{2}\right)$, para o levantamento das ocorrências com altura $\geq 3,1 \mathrm{~m}$ e $<10,0 \mathrm{~cm}$ de DAP; e um retângulo, com $10 \mathrm{~m}$ de largura por $25 \mathrm{~m}$ de comprimento $\left(250 \mathrm{~m}^{2}\right)$, para o levantamento das árvores com DAP $\geq 10 \mathrm{~cm} \mathrm{e}<20 \mathrm{~cm}$.

A alternativa de um conglomerado em forma de cruz é apresentada na Figura 3. A vantagem

Ciência Florestal, v.6, n.1, 1996 
deste conglomerado é a facilidade de instalação no campo, pois necessita de um ângulo reto apenas. E a desvantagem é o maior deslocamento improdutivo, para a medição das subunidades, e o aumento da área total coberta pelo conglomerado.

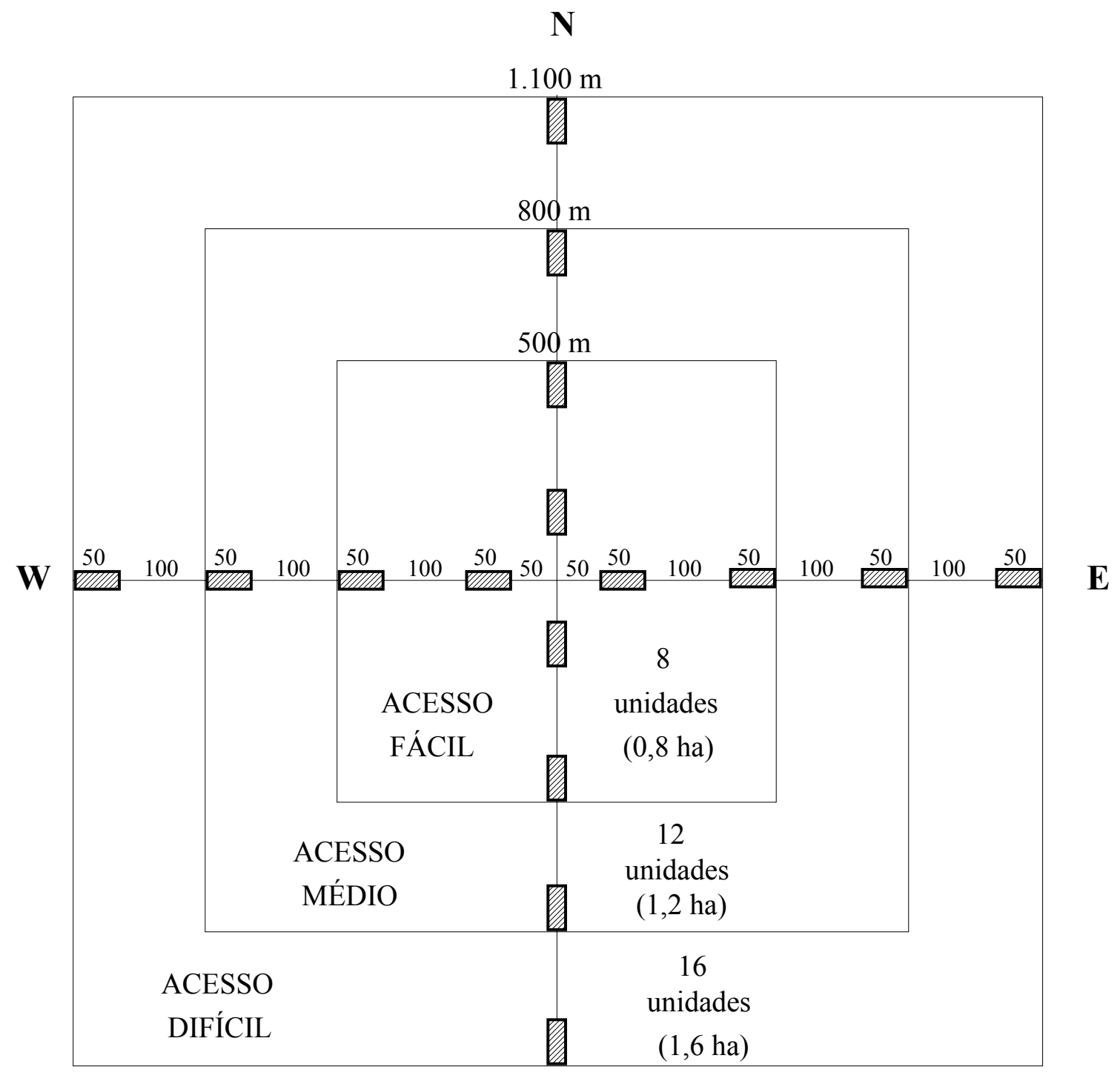

$\mathbf{S}$

FIGURA 3: Conglomerado alternativo para florestas nativas subtropicais, proposto ao IFN do Brasil.

\section{Conglomerado para florestas nativas tropicais}

Considerando-se os estudos desenvolvidos por PÉLLICO NETTO (1969) e QUEIROZ (1977), bem como a tradição de uso na Região Amazônica, propõe-se o uso do conglomerado cruz de malta, para condições de fácil acesso, e sua implementação para condições médias e difíceis de 
acesso, como mostra a Figura 4, cuja eficiência deve ser analisada experimentalmente.

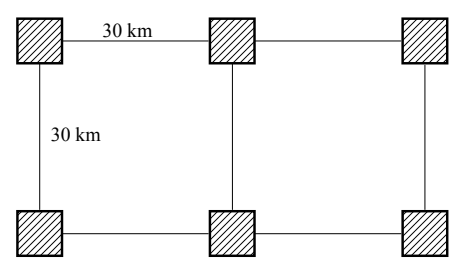

SUBUNIDADE

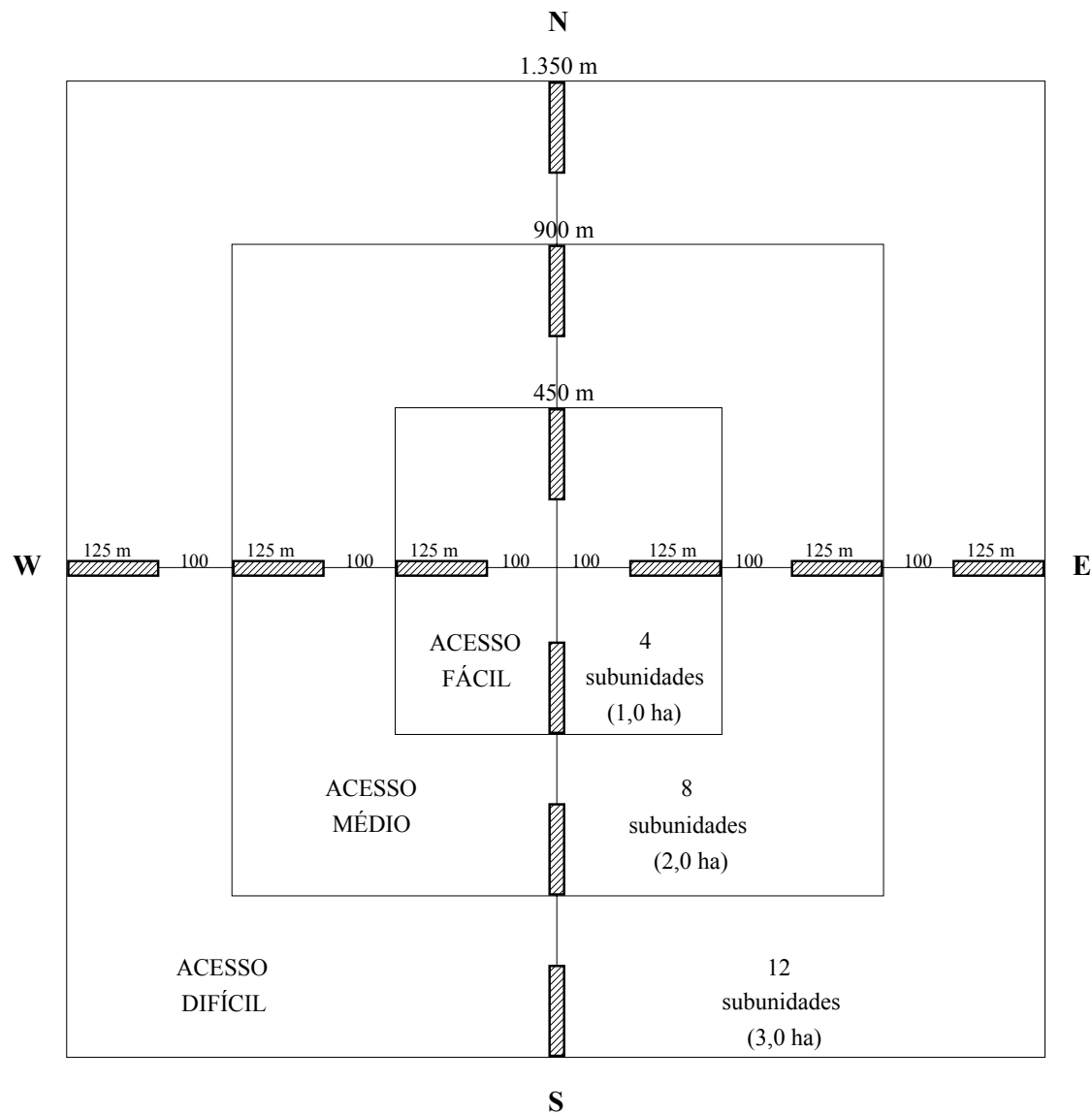

FIGURA 4: Conglomerado para florestas tropicais, proposto ao IFN do Brasil.

Em condições de fácil acesso à área florestal, o conglomerado seria a cruz de malta tradicional, com modificação nas subunidades, que teriam $20 \mathrm{~m}$ de largura por $125 \mathrm{~m}$ de comprimento, nas quais seriam medidas todas as árvores com DAP $\geq 20 \mathrm{~cm}$. Este conglomerado estaria contido em um quadrilátero com $450 \mathrm{~m}$ de lado, o que representa 20,25 ha de área total e 1,0 ha de área amostrada, e seria concluído em 1 dia de trabalho.

Em condições médias de acesso, o conglomerado teria 8 subunidades, contidas em um quadrilátero com $900 \mathrm{~m}$ de lado, 81,0 ha de área total e 2,0 ha de área amostrada, previsto para ser concluído em 2 dias de trabalho de campo.

Em condições de difícil acesso, o conglomerado teria 12 subunidades, contidas em um 
quadrilátero com $1.350 \mathrm{~m}$ de lado, área total de 182,25 ha e área amostrada de 3,0 ha, previsto para ser concluído em 3 dias de trabalho de campo.

As subunidades dos conglomerados propostos para florestas tropicais também seriam compostos pelas 4 subamostras sugeridas para as florestas nativas subtropicais.

\section{Conglomerado para florestas plantadas}

Para as florestas plantadas, propõe-se um conglomerado quadrado, com $300 \mathrm{~m}$ de lado, composto por 24 subunidades circulares distribuídas nos seus lados a cada $75 \mathrm{~m}$, sendo 8 para avaliação de volume, 8 para avaliação de regeneração e 8 para avaliação de tocos, como mostra a Figura 5.

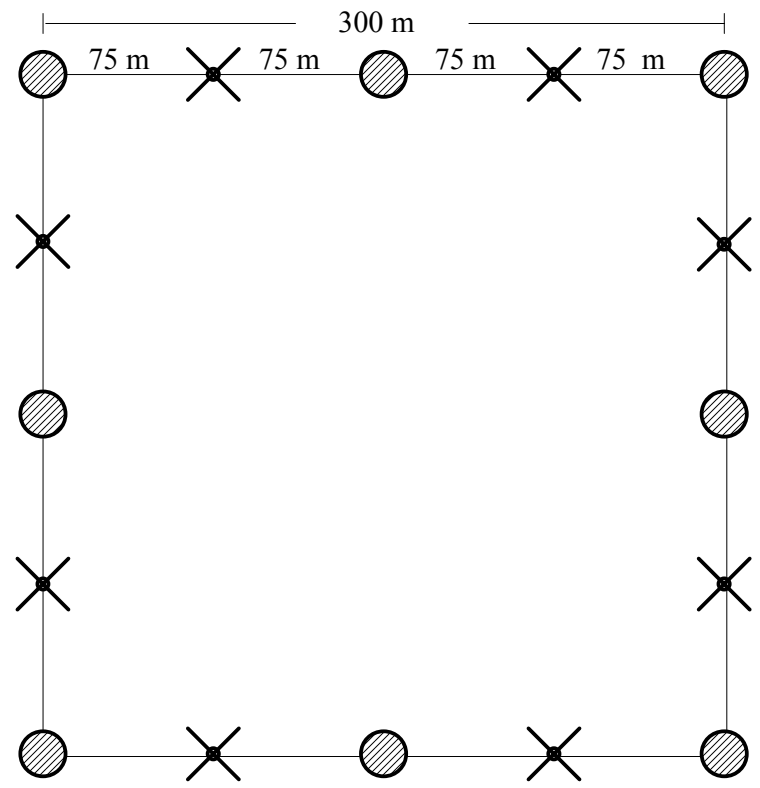

\section{SUBUNIDADES}

Volume

¿ Regeneração

Tocos

FIGURA 5: Conglomerado para florestas plantadas, proposto ao IFN do Brasil.

A subunidade para avaliação de volume seria um círculo com $600 \mathrm{~m}^{2}$ de superfície $(13,82 \mathrm{~m}$ de raio), na qual seriam levantadas todas as árvores com DAP $\geq 5,0 \mathrm{~cm}$.

A subunidade de regeneração seria um círculo de $10 \mathrm{~m}^{2}$ (raio de $1,78 \mathrm{~m}$ ), onde seriam levantadas as ocorrências florestais, a partir de $10 \mathrm{~cm}$ de altura até $5,0 \mathrm{~cm}$ de DAP.

A subunidade de toco seria igual a de volume, com $600 \mathrm{~m}^{2}$ (raio de 13,82 m), aplicada somente em áreas que tivessem sofrido cortes, onde seriam levantados os tocos das árvores cortadas, identificado-se a espécie e o ano do corte.

Um conglomerado alternativo, em forma de cruz, para florestas plantadas, é apresentado na Figura 6, inserido em um quadrilátero de $450 \mathrm{~m} \mathrm{x} 450 \mathrm{~m}$ (20,25 ha), com 8 subunidades para avaliação de volume, 5 para regeneração e 5 para tocos, distribuídas nos braços da cruz com uma distância de $75 \mathrm{~m}$ entre os centros das subunidades. 


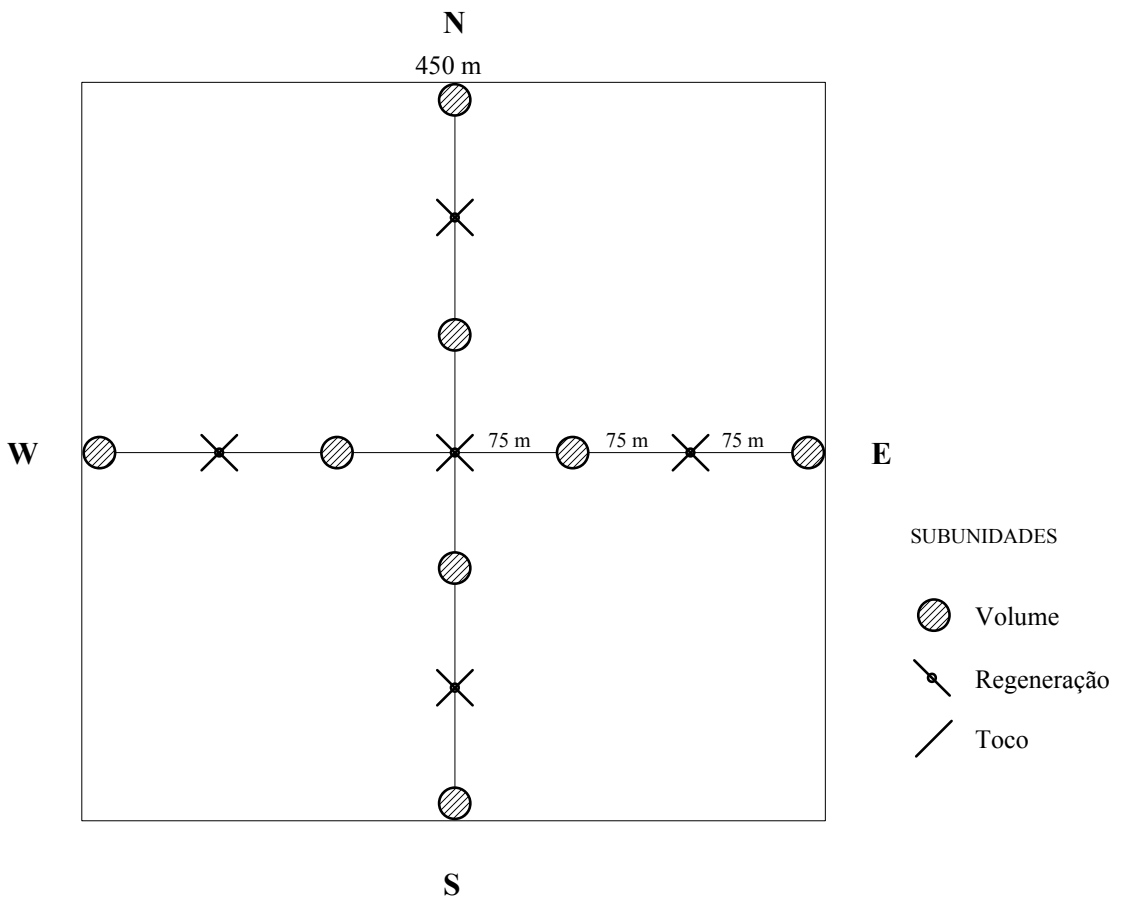

FIGURA 6: Conglomerado alternativo para florestas plantadas, proposto ao IFN do Brasil.

\section{Arvores-amostra}

Em cada subunidade de volume, seriam selecionadas árvores-amostra, para a elaboração de equações volumétricas e, no caso de coníferas, para determinação de incremento e idade.

\section{Coleta de informações}

As informações coletadas seriam divididas em 6 grupos área florestal; sítio; estoque volumétrico, ingresso, crescimento e mortalidade; regeneração; corte periódico; e informações adicionais.

\section{Informações gerais sobre a área florestal}

Este grupo incluiria informações sobre a localização da área, proprietário, tipo de propriedade, atividade principal, acessibilidade, extensão da floresta, classificação florestal, uso atual e potencial da floresta, sistema de manejo usado, principais produtos e subprodutos extraídos da floresta, mananciais hídricos existentes, influências humanas sobre a área florestal, tratamentos silviculturais necessários para os próximos 5 anos, entre outras.

\section{Informações de sítio}

Este grupo incluiria a coleta de dados necessários para estimar índices de sítio nas florestas plantadas, e para caracterizar os sítios nas florestas naturais, bem como avaliar seu grau de utilização. 


\section{Estoque volumétrico, ingresso, crescimento e mortalidade}

O estoque volumétrico seria obtido através dos dados coletados nas subunidades dos conglomerados temporários e permanentes. Nos conglomerados permanentes, todos os indivíduos seriam numerados e localizados espacialmente, através de suas coordenadas.

Os dados de crescimento seriam obtidos nas remedições dos conglomerados permanentes e através de análise de tronco total e parcial, no caso de espécies coníferas.

Os dados de mortalidade seriam obtidos, principalmente, nos conglomerados permanentes, mediante a identificação e registro das árvores mortas, bem como a causa e o ano provável de sua morte.

\section{Regeneração}

Como regeneração, propõe-se que sejam consideradas as ocorrências de espécies arbustivas e arbóreas das florestas nativas maiores que $10,0 \mathrm{~cm}$ de altura e menores que 10,0 cm de DAP; e, para as florestas plantadas, as ocorrências maiores que $10 \mathrm{~cm}$ de altura e menores que $5,0 \mathrm{~cm}$ de DAP. A regeneração seria levantada nas subamostras específicas.

\section{Corte periódico}

As informações sobre o corte periódico seriam obtidas através das subunidades de toco, nas florestas plantadas, e das subunidades específicas dos conglomerados aplicados nas florestas nativas. Nestas subunidades, os tocos seriam enumerados, medidos seus diâmetros, identificado a espécie e estimado o ano do corte.

\section{Informações adicionais}

Este grupo incluiria o levantamento florístico, da fauna silvestre e disponibilidade de alimentos, de parâmetros recreacionais e eco-turísticos, de níveis de poluentes e sedimentos na água, das ocorrências de pragas e incêndios florestais, bem como das informações específicas definidas pelos Estados ou Regiões.

\section{Registro das informações}

As informações seriam registradas diretamente em coletores de dados e após transferidas para microcomputadores, as quais acompanhariam as equipes de campo, visando realizar a primeira consistência ainda no campo.

\section{Processamento dos dados}

O processamento dos dados seria feito pelas instituições executoras, através de sistemas computacionais especialmente preparados para o IFN. As modificações nos programas ocorreriam em função das informações específicas de cada Estado.

\section{Elaboração de relatórios e divulgação dos resultados}

Os relatórios dos inventários seriam elaborados pelas instituições executoras, para cada Estado, usando-se um modelo padrão. A partir dos relatórios Estaduais, seria elaborado o relatório 
nacional e um sumário executivo.

\section{Banco de dados e informações florestais}

Todos os dados e informações do IFN seriam armazenados em bancos de dados, que poderiam ser acessados pelos usuários, através de teleprocessamento.

\section{ESTRUTURA OPERACIONAL DO SISTEMA}

$\mathrm{Na}$ estrutura operacional do sistema, considerou-se a extensão territorial do país e de seus recursos florestais, a dimensão da tarefa, os recursos financeiros, humanos e materiais necessários e a infraestrutura envolvida no trabalho, buscando um modo operativo que tornasse o sistema exeqüível e viável.

A sistemática de implantação proposta - em 5 etapas, em um período de 10 anos - tem base na experiência internacional, segundo a qual a maioria dos países implantou seus IFN em etapas gradativas, visando consolidar e aperfeiçoar as metodologias, treinar recursos humanos e adequar os trabalhos às disponibilidades de recursos humanos e financeiros.

\section{Recursos financeiros}

Face a soma considerável de recursos financeiros necessários para a execução do IFN, sua implantação em etapas regionais diluiria esses recursos em 10 anos, tornando-o mais acessível ao país. Além disso, poderia ser pleiteado um financiamento internacional para o IFN, junto às entidades que apoiam programas dirigidos à conservação ambiental.

\section{Trabalho de campo}

O trabalho de campo poderia ser desenvolvido a partir de três formas de organização das equipes nacionais permanentes, regionais temporárias, ou regionais permanentes.

\section{Equipes nacionais permanentes}

Esta organização teria as vantagens decorrentes do aperfeiçoamento das equipes e da homogeneidade de critérios em nível nacional. Porém, só é viável em países com pequena extensão territorial, devido a exigência de mobilidade das equipes em todo o país. Portanto, esta possibilidade seria inadequada para o caso do Brasil.

\section{Equipes regionais temporárias}

Nesta organização, as equipes seriam formadas exclusivamente para o trabalho de campo e destituídas após sua conclusão. Esta alternativa seria desaconselhável para o IFN porque não permitiria o aprimoramento do trabalho e melhoria na eficiência das equipes.

\section{Equipes regionais permanentes}

As equipes seriam compostas, em cada Estado ou região, treinadas e ocupadas exclusivamente nas tarefas do inventário. Isto permitiria o aperfeiçoamento do trabalho e a realização de levantamentos adicionais de interesse nacional ou Estadual.

Esta organização é usada pela Suécia e a Finlândia desde 1953 e 1960, respectivamente, e 
seria a organização ideal para o IFN do Brasil.

\section{Treinamento e controle das tarefas}

Propõe-se que, antes da sua implantação do IFN, seja realizado um treinamento das equipes de campo, para homogeneizar os critérios adotados. Propõe-se, também, que as instituições executoras estabeleçam equipes de controle e confiram $10 \%$ dos conglomerados, para avaliar a qualidade da coleta dos dados e quantificar os erros não amostrais.

\section{Estrutura operacional proposta}

Para viabilizar o IFN, torná-lo eficiente e garantir sua continuidade, propõe-se que o sistema seja implantado por Regiões, iniciando pela Região Norte, no período de 10 anos, através de equipes regionais permanentes.

O início pela região Norte é justificado por concentrar os recursos florestais mais importantes do país e pela necessidade de informações contínuas sobre o estado e a dinâmica dos ecossistemas florestais da Amazônia, indispensáveis para o planejamento e controle do uso dos recursos florestais em base sustentável.

A manutenção de equipes regionais permanentes seria viabilizada mediante a transformação do IFN em um processo anual contínuo, repetindo-se $20 \%$ da estrutura amostral a cada ano. Assim, a cada 5 anos o inventário seria totalmente repetido e, anualmente, se teria informações atualizadas de cada região e do país.

\section{CONCLUSÕES}

A análise da proposição de um sistema de inventário florestal nacional para o Brasil permite concluir que:

a) O IFN não é um instrumento auxiliar exclusivo de planejamento e controle dos recursos florestais, mas também para tomada de decisões e coordenação das políticas florestal, agrária e ambiental;

b) O sistema proposto possui as características desejáveis principais de um sistema de inventário florestal nacional apresentadas por CUNIA (1985);

c) A proposta do sistema está fundamentada na experiência internacional analisada e agrega as inovações mais recentes aplicadas no mundo;

d) Se aplicado tal como foi proposto, o inventário florestal nacional se transformaria em um processo anual contínuo e dificilmente sofreria solução de continuidade;

e) O sistema permite a associação e comparação de resultados dos inventários estaduais ou regionais, face a padronização da metodologia;

f) O sistema substituiria a maior parte dos inventários florestais realizados pelo setor público, racionalizando a aplicação de recursos e evitando duplicação de esforços;

g) O sistema permitiria definir o volume de madeira a ser cortado, anualmente, em cada Estado, Microrregião, e no País, de acordo com o crescimento e produção de suas florestas, bem 
como monitorar a área desmatada e estimar o volume realmente explorado no ano ou período anterior.

h) O sistema, uma vez implementado, dotará o país de um instrumento auxiliar moderno e eficiente, para o planejamento, administração e controle de seus recursos florestais, e auxiliará sua inserção no programa de qualidade total para o meio ambiente, a ser definido pela ISO 14.000.

\section{REFERÊNCIAS BIBLIOGRÁFICAS}

BERMUDEZ, R. M. Tecnicas usadas en los inventarios forestales de Mexico. Ciencia Forestal, México, v.7, n.37,p.46-64, 1982.

BONNOR, G. M. Forest inventories in Canada. Forestry Abstracts, v.43, n.4, p.201-211, 1982.

BRENA, D. A. Inventário florestal nacional: proposta de um sistema para o Brasil.

Curitiba, 1995. 226 p. Tese. (Doutor em Ciências Florestais). Setor de Ciências Agrárias, Universidade Federal do Paraná.

CUNIA, T. Main objectives and desirable characteristics of national forest inventory systems. In: Pelz, D. R.;Cunia, T. (editores) NATIONAL FOREST INVENTORY IN EUROPE, Freiburg : Forstliche Biometrie Universitat Freiburg, 1985. p.01-19.

ERIKSSON, B. The Swedish National Forest Inventory. In: Pelz, D. R.;Cunia, T. (editores) NATIONAL FOREST INVENTORY IN EUROPE, Freiburg: Forstliche Biometrie Universitat Freiburg, 1985. p.36-70.

JANSEN, J. J.; DAAMEN, W. P. ; RITSKES, T. M. et alii The fourth national forest inventory in the Netherlands. In: Pelz, D. R.;Cunia, T. (editores) NATIONAL FOREST INVENTORY IN EUROPE, Freiburg : Forstliche Biometrie Universitat Freiburg, 1985. p.151162.

KUUSELA, K. The National Forest Inventory in Finland. In: Pelz, D. R.;Cunia, T. (editores) NATIONAL FOREST INVENTORY IN EUROPE, Freiburg : Forstliche Biometrie Universitat Freiburg, 1985. p.71-82.

MAHRER, F. Methodology and execution of the Swiss National Forest Inventory. In: Pelz, D. R.; Cunia, T. (editores) NATIONAL FOREST INVENTORY IN EUROPE, Freiburg: Forstliche Biometrie Universitat Freiburg, 1985. p.106-122.

MARTÍNEZ MILLÁN, F. J. The second National Forest Inventory of Spain. In: Pelz, D. R.; Cunia, T.(editores) NATIONAL FOREST INVENTORY IN EUROPE, Freiburg : Forstliche Biometrie Universitat Freiburg, 1985. p.71-82.

PÉLLICO NETTO, S. Factors affecting cluster sampling. Syracuse, 1968. 112 p. Dissertação. (Mestrado).

PÉLLICO NETTO, S. National Forest Inventory in Brazil. In: XVII FOREST MEETING OF IUFRO (1981 : Kyoto, Japan). Proceedings ... Kyoto :IUFRO, 1981.

QUEIROZ, W. T. Efeitos da variação estrutural em unidades amostrais na aplicação do processo de amostragem em conglomerados nas florestas do Planalto do Tapajós. Curitiba, 
1977. 108 p. Dissertação. (Mestrado em Ciências Florestais). Setor de Ciências Agrárias, Universidade Federal do Paraná.

SCHREUDER, H. T. \& BONNOR, G. M. Forest inventories in the United States and Canada. Forestry Chronicle, v.63, n.6, p.431-434, 1987. 